\title{
Theme Schools: From Manifesto to Paradigm for Undergraduate Students
}

\section{By David W. Norton and Karim-Aly S. Kassam}

\section{INTRODUCTION}

I N SCIENCES, when anomalies or discrepant observations generate a crisis, so that the old way of looking at things no longer suffices to explain or predict observable events, scientists construct a new paradigm (Kuhn, 1996).

Despite vast differences in our backgrounds and in the attributes of our widely separated home institutions, we have arrived at strikingly similar perceptions of the need to fashion a new paradigm within undergraduate education. By aligning the anomalies and assembling experiences from several corrective efforts within the old paradigm, we have begun to distil some tenets of a coherent rationale for student-centred learning, built around the concepts inherent in a "theme school." These tenets are especially relevant to small, widely dispersed northern communities. Much of the following discussion originates in our shared disappointments with the effectiveness of education by the traditional Euro-American undergraduate paradigm when applied to northern environments and rural communities. Nevertheless, we are not institution-bashing: we owe much, after all, to the institutions that provided us with a point of departure for exploring alternatives and supplements.

\section{Genesis: Serving Nontraditional Students}

Paradigm, in the sense of a pattern of thinking about matters, makes a good starting point for sharing our emerging understanding of what we mean by the term, "theme school." In the ensuing discussion, everything flows from the fundamental attitude we have adopted of "serving" students. With that attitude operating as a manifesto, we must be attentive to our students' attributes. Our students are primarily undergraduates; however, that bracket today embraces an extraordinarily diverse population. Community colleges, continuing and adult education, second-career development, and distance education are among today's catalysts of diversification.

The "cohort model" of undergraduates-as belonging to one of four cohorts (= levels or year-classes) of campus residents, who exit undergraduate life at 22 or 23 years of age after their fourth or fifth cloistered year of uninterrupted study, degrees in hand, but still innocent of such life experiences as parenthood-no longer corresponds to the demographic realities spreading in North America. Instead, undergraduate classes may now bring together mixtures of generations and of cultural and experiential backgrounds. Such mixtures are unrecognized by the traditional cohort image of campus life. Moreover, students' points of entry to and exit from higher education, the rewards they seek for their academic efforts, the directions in which they are headed, and their rates of progress also vary widely. This seeming randomization of students' self-identities, aims, and velocities with academic tasks can be confusing to educators like us. Worse, it can be downright paralytic to any levels of academic management that still force-fit the cohort model to environments where it is inappropriate.

Although traveling figuratively in opposite directions, each of us started by paying close attention to qualities of our respective students in seeking to adapt our teaching and learning paradigms. On Alaska's North Slope, the journey began when the community staged a three-day conference at Barrow in 1990 to address the problems of science education throughout the Kindergarten-to-Ph.D. spectrum. From an event that was focused on a disciplineperceived problem, a fundamental question was crafted for educators: What works, given the special strengths and appetites that rural and northern students bring to the learning enterprise? (Norton, 1992). In Calgary, by contrast, Dr. Cooper Langford, Vice President for Research of the University of Calgary, asked the Arctic Institute to develop a plan of action for theme schools, as a means to increase the roles of on-campus research institutes in undergraduate education. That request enabled the Arctic Institute's Theme School in Northern Planning and Development Studies to craft its similar fundamental question: How do we prepare students to contribute meaning fully to rural and northern communities? (Kassam, 1994).

\section{COMING TO THE THEME SCHOOL PARADIGM}

\section{Restructuring Individual Natural Science Classes}

By asking the fundamental question posed in Alaska, Norton found that Iñupiat and non-Iñupiat students of a wide age span applied their skills more effectively when learning became a group enterprise of "sharing," rather 
than individual competing against individual. These students also learned most effectively when the pace of class discussions permitted "side trips" to explore and relate topics that North American universities normally regard as the territories of disjunct disciplines or faculty specialties. Accordingly, several classes were developed from Barrow to capitalize on those two student strengths. The University of Alaska exercises a well-defined process which encourages educators to propose new, experimental classes. After several semesters, experimental courses may demonstrate worthiness for permanent adoption to the University's menu of undergraduate classes. The following two cases illustrate gradual "upward" steps toward thematic approaches inherent in the theme school paradigm.

Case 1: Two authors collaborated in an innovative, interdisciplinary or thematic chronicling of steps in development of scientists' theories on organic evolution (Edey and Johanson, 1989). Their book combines the topical analyses of the investigative journalist (Edey) and the biologist (Johanson) to take precisely the holistic, story-telling approach to interdisciplinary topics in natural sciences that should appeal to students on Alaska's North Slope. A trial class was tailored to rural Alaska students' perceived need for a short introductory seminar (two semester credit-hours, instead of the usual four for science classes), using this book as its pivotal support reading. Partly because of its unconventional credit value, the resulting class never attracted enrolments of more than 10 students. Students nevertheless persisted well; the ratio of completions to registrations was high throughout the threeyear trial period. The Biology Department at Ilisagvik College's accrediting campus of the University of Alaska Fairbanks (UAF), noting this persistence ratio, awarded the seminar permanency as BIOL 181 in the UAF undergraduate catalog of classes.

Case 2: Arctic students from the community of Point Hope (Tiqigaq) requested another trial seminar, which has developed since 1994 in a thematic manner. An unsettling discovery in 1992, related to Project Chariot, was widely reported by Alaska's news media. Project Chariot was a 1950s scheme to blast a harbour on the coast near Point Hope with buried nuclear bombs. In 1962, the year after environmental studies for Project Chariot had concluded, a small amount of radioactive tracer material was left buried by other researchers doing independent follow-up studies at Ogoturuk Creek $(50 \mathrm{~km}$ southeast of Point Hope). The North Slope Borough insisted, on the grounds of public health, that the U.S. government excavate the site and dispose of the material outside the Arctic. Alarm over the legacy of half-forgotten events from a generation and a half earlier was bewildering and distressing to students, many of whom feared that cancer risks to themselves and family were elevated by the tracer compounds left in their environment. Students sought reassurance through learning the story behind Project Chariot and its legacies, both local and global. Shortly after Dan O'Neill's (1994) award- winning account of Project Chariot became available, students persuaded Ilisagvik College to offer a seminar which adopted the title, "The Project Chariot Story." After three semesters as a one-credit trial seminar in Biology offered by distance delivery throughout Alaska's North Slope, the course was expanded in 1996 to a three-credit class, offered University of Alaska-wide in a "multi-site, multi-instructor course (MSMIC)" format (Norton, 1997). The interdisciplinary nature of the class is shown in the fact that by the time of its first three-credit offering, it had been recognized by four different disciplinary departments at UAF for credit towards a bachelor's degree major in any of these fields of concentration. By UAF's creative process of cross-listing, this one course thus appeared as four entries in the course catalog: Biology (BIOL 295), Alaska Native Studies (ANS 295), History (HIST 295), and Rural Development (RD 295). The resulting student body attracted to this MSMIC was predictably diverse, and their discourse lively and creative, reflecting strengths of interest from the several contributing fields of concentration.

\section{Museum Studies in Alaska and Alberta}

Cases 3 and 4: Alaska's full undergraduate theme school is illustrated by the Museum Studies programme, in which classes are now made available Alaska-wide in the MSMIC format. Like the Nickle Arts Museum's Theme School in Museum and Heritage Studies at the University of Calgary, Alaska's programme was designed as a minor, adjunct to a bachelor's degree with majors such as Anthropology. The undergraduate Museum Studies examples of theme school developments in Alaska and Alberta are described elsewhere, in an analysis that summarizes their significant contributions as:

1. Challenging the notion that only graduate students are qualified to benefit from the transdisciplinary nature of Museum Studies;

2. Demonstrating the feasibility of stimulating and nurturing enthusiastic activity by students at sites often neglected as impossibly remote (geographically or culturally) from mainstream academic and museum centers of activity;

3. Partnering among academic institutions, teaching museums, and regional associations of museums to enrich and assure the quality of student experiences (Norton and Crowell, 1997).

\section{The Arctic Institute's Theme School in Northern Planning and Development Studies (NPDS)}

Case 5: Unlike Ilisagvik College, which took a gradualist approach to thematic learning paradigms (Cases 1 and 2), the Arctic Institute had to conceive its NPDS Theme School all at once, in full and coherent programmatic entirety, in 1995 (Kassam, 1995). That was the year in which the Institute marked its fiftieth anniversary with a 
commitment to self-renewal through new initiatives in undergraduate education. It was coincidentally the year that the University of Calgary made its commitment to connect campus research institutes more closely with undergraduate learning. These twin commitments established a fertile environment for creative thinking. The task was nonetheless daunting on two fronts:

1. How could a 50-year-old institute (on a 29-yearold university campus) weave its efforts into the notoriously tribal fabric of undergraduate disciplinary education?

2. How could the courses of study be fashioned thematically into a new, progressive synthesis that would appeal to a critical mass of diverse undergraduates?

On the first front, two theme school initiatives (Theme School on New Materials and their Impact on Society, and Theme School on International Justice and Human Rights) had been started by McMaster University in 1993 (McMaster University, 1995). These furnished the Arctic Institute with helpful precedents, patterns for how the interdisciplinary NPDS Theme School could mesh with the dominant fabric of undergraduate programmes in disciplinary studies, and provided a quick study in the jargon of academia.

On the second front, there was no helpful precedent. No programme of similar content with even grudging tribal acceptance could be found elsewhere for convenient adaptation. This challenge thus enabled the Arctic Institute to begin on a clean slate. The Institute's approach took form with the following eight thematic courses linked together into a minor programme:

- NPDS 301 and NPDS 303 establish the strong interdisciplinary foundation. These courses critically examine the theory and practice of community development with specific case studies from Canada's North and elsewhere.

- NPDS 305 examines the role of traditional environmental knowledge and its significance to northern development. Participatory research methodologies are introduced. Prerequisites: NPDS 301 and 303.

- NPDS 307 uses Geographic Information Systems (GIS) as a tool for the organization, storage, and management of community land use information. The course covers methods of data acquisition, government and industry data resources, basic GIS skills, and resource management methods, using GIS as a tool. Prerequisites: NPDS 301, 303, and 305.

- NPDS 309 develops additional professional skills in gender analysis, strategic planning, and nonadversarial conflict resolution. Prerequisites: NPDS 301 and 303.
- NPDS 311 further develops professional knowledge of community planning in northern Canada. It provides a "toolbox" of skills essential for individuals who engage in community planning. Prerequisites: NPDS 301, 303, and 309.

- NPDS 400, a group project, enables NPDS students to prepare funding proposals for economic development projects or to undertake research on economic development for a community. Prerequisites: Enrolment in the NPDS minor and NPDS 311.

- NPDS 500, the final NPDS course, has students combine all of the skills learned in the previous four courses of the minor in an individual project, accomplished through an off-campus internship (Kassam, 1995).

After receiving University approval in late July 1995, the Arctic Institute's NPDS Theme School began operations in September of that year. The Theme School began with 16 students, more than half of Aboriginal descent, and more than half from north of $60^{\circ} \mathrm{N}$ latitude. The majority were female and mature (over the age of 30). Many had dependents, and some were de facto single parents. They did not match the "cohort" model of undergraduate students. Their majors included Ecology, Linguistics, Geography, Sociology, Business Management, Nursing, Psychology, Communications Studies, and Political Science. In every sense they presented both diversity and interdisciplinary interests.

\section{NAVIGATIONAL HAZARDS FOR THEME SCHOOLS}

Now in its second year, the NPDS Theme School is a work in progress, as are theme schools at the University of Alaska and McMaster University and the other three University of Calgary theme schools (Fig. 1). Troughs of crisis and peaks of achievement have punctuated its formative months. Rather than handwringing over specific troughs, or exulting over specific peaks at the NPDS Theme School, we turn to constructing one set of generalizations by blending experiences from Alberta and Alaska.

\section{Identifying Successful Outcomes}

Benchmarks are sought by the academic review process, as gauges for successful stages in development by any new undergraduate programme of study. Adopting the default measure of head-counting enrolees-essentially a popularity contest - in a young programme has proved so perilous, as illustrated below, that almost any alternative may be preferable. For example, persistence by students, as in Case 1 above, is more reflective of the effectiveness of a course of study. On the other hand, success is sometimes indicated by the reverse, or student mobility, as discussed below (see Student Transience). 


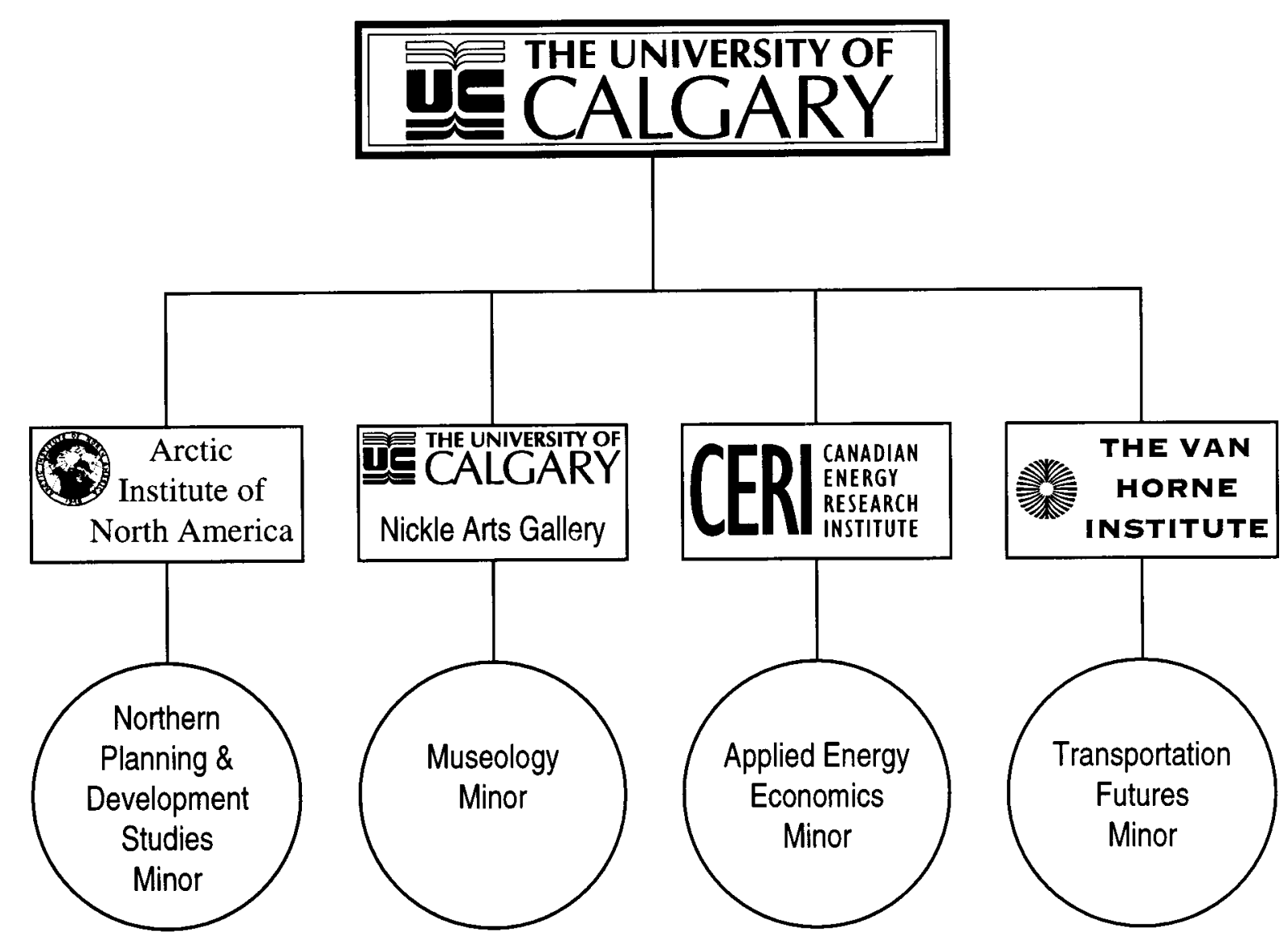

FIG. 1. Theme schools at the University of Calgary.

\section{Attracting Students to the Theme School}

UAF's former Chancellor, the late Howard Cutler, once commented, "An invitation to everybody is an invitation to nobody." We have found that during their formative semesters, new programmes or courses must recruit students individually. Before a niche in academic tradition is both secured and recognized, the initiative-taking educator faces personal recruiting, advising, fundraising, and screening, as well as teaching. Nobody else will do these jobs effectively, and almost nobody will enrol solely on the basis of posted notices or entries in an academic calendar.

\section{Grading and Credit}

No practice by Euro-American higher education is more gut-wrenchingly difficult to apply to theme school students than its traditional undergraduate grading system. The rhetorical "How do you 'flunk' a museum?" (Spiess, 1996) fits the theme school dilemma. For instance, in the NPDS Theme School, weighting assigned to the students' work is nontraditional. First, emphasis is placed on active class participation and presentations in a seminar format. Second, research paper writing is also a focus for course assessment. Students are provided workshops in acquiring effective research and paper-writing skills. The third component is an in-class midterm examination. The fourth component is a final take-home essay examination, which includes questions that relate to practical and societal applications of the learning that took place.

We foresee getting away from awarding grades to individual students, at least in some parts of thematic programmes. From theme school students, as from graduate students, we expect consistently outstanding contributions by each participant. One alternative to traditional grading may be to vary the number of credits, awarding three credits for completing a course with "very good" achievement and four credits for "brilliant" achievement.

\section{Student Transience}

We were slow to notice it, but inherently conflicting measures of student "success" can develop between traditional academic intramural tracking and a less parochial, extramural tracking of students, particularly if two or more institutions collaborate across different levels of academic hierarchy. At length, a paradox caught our attention: virtually no students in Alaska were completing all two or three years' worth of classes to qualify for a Minor in Museum Studies, but more than ten students had used the momentum they picked up while completing half the minor's requirements to move on to museum internships, postgraduate Museum Studies programs, or outright employment at museums. 
This paradox is further illuminated by an analogy from the world of professional sports, which we call the Farm Team's Dilemma. At the two highest talent levels in the hierarchies of North American professional hockey and baseball, when a farm team coach effectively improves players' athletic skills, a major league team snatches those players away. Hierarchy-wide, players and other coaches count that farm team's losses of polished players as positive measures of coaching success. The dilemma for the farm team coach is that his own team's chances of winning the minor league championship-a conflicting indicator of coaching success-diminish as each improved player moves upward during a season, because each vacated slot on the roster is filled by a less improved athlete. If restless local fans want top players to remain with the team long enough to carry it to a championship, the temptation may arise to downplay coaching individuals, thus to increase team success and ticket sale revenues to the franchise.

The implications of this analogy are clear for theme school approaches. Students are no more the intellectual property of an undergraduate institution than minor league athletes are the property of their farm-team franchise. Rather, students "belong" to a wider community's process, essentially to a talent stream. In this context, student mobility is to be applauded. Since theme schools offer a student only relatively weak symbolic recognition for an undergraduate minor, students are not held tightly by bonds of allegiance to an institution. Although undergraduate "franchises" routinely track intramural accomplishments and events (courses completed, grade point averages maintained, and degrees awarded), many are grievously short-sighted toward students' extramural achievements. Today's students, however, move laterally (transferring, taking time away to gain practical experience or the finances with which to return) and upward (seeking higher degrees and career achievement). Extramural tracking of students falls largely to educators themselves. This exacting task looms more important in the extended fabric of thematic learning than does intramural tracking.

Our observations suggest that those students who endured a lengthy personal interview and screening process before admission to the NPDS Theme School, and those students who deliberated to the point of soul-searching before deciding to enrol in Museum Studies or in Alaska's thematic science classes, have persisted or vaulted ahead. By and large, those students who took less time to consider their commitment at the outset have not persisted. In other words, observably thoughtful students tend to persist.

\section{Academic Scheduling}

Marked variations in seasonal community activity are naturally pronounced at high latitudes, frustrating success in the North by Euro-American academic schedules originally designed around mid-latitude agricultural seasons. Students at Barrow ( $71^{\circ} \mathrm{N}$ Latitude) "normally" have to start a second-semester (spring-semester at UAF) class in the sunless tranquillity of January but not finish until after the sun is nearly constantly above the horizon, in late April. More to the point, students are tempted to bolt from classrooms in April to join others outdoors, readying sled trails across shorefast ice for the imminent spring whale harvest. Again in the fall semester, the "normal" startup of classes has to compete with fall whaling for students' attention. Thematic courses have achieved some success at fashioning a compromise, by compressing class schedules in toward the middle weeks of each midlatitude academic semester. To the degree that theme schools may thrive by extending into small communities where such environmentally linked spikes of activity will rule, compression or relaxation of traditional academic timetables may work.

\section{Support for Students}

Adversities of every conceivable form have arisen in our combined experiences with theme schools and thematic courses. Yet students are remarkably resilient, provided that they grasp the implications of being in a studentcentred programme, where educators are partners rather than remote and neutral. In the first weeks of the NPDS Theme School's operation, a crisis arose over delayed receipt of student stipends from a single source. Clearly, the Institute needed a more diverse and reliable safety net for them. Between September and December 1995, \$91 000 was raised for a scholarship endowment. With \$20000 in seed money, the Arctic Institute attracted $\$ 11000$ from the University of Calgary, $\$ 10000$ from Mrs. Lois Currie (wife of a former Chairman of the AINA Board of Directors), and $\$ 50000$ from Amoco Canada. This generosity enabled the Institute to establish its Amoco Canada and Gerald Thompson scholarships. The first three student awards were made in September 1996 (AINA, 1996b).

Another challenge developed when three students from the programme were offered internship opportunities sooner than anticipated (AINA, 1996a). There was no funding allotted in the first year to conduct the NPDS 400 internship course because enrolments had not been expected until two years later. Support again had to be sought from the private sector. Furthermore, the internship was not initially conceived as paid employment, but only as experience rewarded by academic credit. In an increasingly hostile climate for student financing, however, it became clear that paid employment was essential to persistence, lest students need to find part-time jobs and not be able to devote the necessary time to their internships. In rising to meet these challenges, students could not only see firsthand the supportive roles played by Arctic Institute associates and educators, but they could participate helpfully in the process as team members. Student-centred attitudes are equally pivotal for Alaska's thematic programmes, although single-source support by The Pew Charitable Trusts has temporarily subsidized many students' needs during the period 1995-97. To restate, we see support for 
students as primarily grounded in the educators' positive attitude.

\section{Financial Independence from Budget Strictures}

The challenge of securing stable financial support for theme schools' continuance permeates our concerns. If top levels of academic management are seduced by the tyranny of simplistic arithmetic, through which ever-increasing enrolments are urged upon universities operating with static or diminishing funds, low student head counts threaten to make small interdisciplinary theme schools inviting targets for budget cuts. Recently the U.S. Secretary of the Treasury likened growth for its own sake to the ideology of a cancer cell. Adopting such an invasive ideology would hardly endear theme schools to dominant undergraduate disciplinary units. Those harbouring their own budgetary anxieties would view theme school growth as competition for a slice of the head count. The truth of the matter is that an undergraduate minor is the opposite of invasive; undertaking a minor is not an either-or proposition that excludes a major. In theory, at least, any undergraduate major is strengthened by a recognized minor field of concentration. Moreover, we predict that in time it will be widely recognized that participants in theme schools are to be prized as especially resilient and resourceful students, whose assured progress merits especially generous investment.

In the probationary stages, we anticipate that theme schools' survival will depend on diversifying their sources of support, so that core funding comes from a number of academic institutions and funding agencies and is balanced or matched by support from the private sector.

\section{THE ESSENCE OF THEME SCHOOLS}

We have arrived at the threshold of a synthesis, and pause to reflect on its significance. How can educators in Alaska and Alberta be converging on one theme school paradigm? In linguistics, the notion of "paradigm" is very much a social construct (O'Sullivan et al., 1994:166, 216). It is a shared body of rules emerging from observation and consensus, out of the control of any one individual. By analogy with games of chess, a paradigm (in this case, a language) abides by a set of rules, but the outcomes are varied and determined by the players. Likewise, the theme school concept in the United States and Canada can have diverse manifestations based on coinciding circumstances and analogous premises.

In terms that scientific readership may find more familiar, Kuhn (1996) identifies historical sense, consciousness, dealing with anomalies, and trying alternatives as key steps in the renewing and synthesizing process. Before Charles Darwin introduced a new paradigm, essentialism was a dominant paradigm in natural philosophy (Mayr, 1991:40-42). Carolus Linnaeus, in the century before
Darwin, had introduced the universal practice of assigning two names, reflecting genus and species, to each form of organism (binomial nomenclature: hence, Homo [genus] sapiens [species] for us, and Homo erectus for one of our extinct ancestral species). The Linnaean contribution was pivotal, in that it allowed Darwin and later biologists to organize organic life by degrees of relatedness in their many characteristics. Here, we are figuratively making the transition from the particularities of its several "species," to one "genus" for the idea of theme school. We thus venture now to identify and illustrate the salient ideal properties-the essence-of thematic and theme school approaches.

\section{Theme: The Historical Dimension}

By contrast with the synchronic or panoramic snapshot approach that disciplinary undergraduate classes tend to adopt, theme school students work through the historical development of ideas, theories, protocols, and institutions that gave rise to and explain that which happens to be in vogue at present. In all thematic courses, a strong component of historical consciousness emerges, so that students are called upon to project and extrapolate into the future. T.S. Eliot, in his 1919 essay entitled "Tradition and the Individual Talent," described historical sense as "a perception not only of the pastness of the past, but of its presence" (Eliot, 1932:14). When this approach succeeds through a theme school, we believe that students are predisposed to habits of active, lifelong inquiry.

\section{Interdisciplinary Emphasis}

Theme schools' interdisciplinary minors are designed ideally as bridges by which undergraduates take direct routes to appreciate, experience, and fine-tune the realworld applications of their undergraduate majors. How often do we hear students after graduation from university comment on how ill-prepared for a given career they were by their chosen disciplinary majors? The transcendent concern for undergraduates' life in the dimension stretching beyond campus leads to vital links. In Calgary, for example, the Arctic Institute, in teaching the NPDS Theme School, is linked to the Faculty of General Studies, itself fundamentally structured around interdisciplinary studies. The Nickle Arts Museum is similarly linked to General Studies through its theme school, and further linked both to museums and to professional museum associations off campus. As a part of their course work on the concept of traditional knowledge, NPDS Theme School students were encouraged to apply this concept to further research of their own interest. After their research was complete, they made public presentations to members of the university community, the private sector, and the community at large (AINA, 1996c:7). This was arguably the first time undergraduate students had been expected to make presentations of this calibre at the university, for the 
scrutiny of such a diverse audience. The hallmark of each presentation was that the concept of traditional knowledge was intimately linked to the students' majors, which included Communications Studies, Sociology, Ecology, Linguistics, Geography, and Political Science.

\section{Process and Research Emphasis}

Emphasis on the self-renewing cycles and steps by which scientific inquiry, community development, and the institutional developments of museums unfold are manifestations of the thematic approach in our illustrative cases. This emphasis on process is a conscious departure from static and passive approaches to knowledge, which treat learning as a deposit of fact or a reservoir of expertise to be consumed by the learner. Thus, we apply a construct of dynamic equilibrium to the adventure of learning, in which a theory or model is continually both built up and torn down to make way for models that work better as successive approximations to reality. The necessary corollary to this emphasis on process is to regard and engage undergraduate students not just as information consumers, but also as producers of insight. They, in turn, engage in doubt, research, original inquiry, the synthesis of idea, and its communication-all productive activities that have been classically (and we think, regrettably) reserved for post-baccalaureate academic endeavour.

\section{Research Institute Based}

Theme schools were conceived in part to exploit certain institutes' and museums' expertise and excellence through informing and involving students in their "leading-edge" research. By their very nature, these institutions have strong links to private and community sectors. Thus, they are suited to teaching these minor degree programmes and spanning the gap between theoretical and practical; they are sensitive to new developments outside established academic fields, and their spheres of activity are directly relevant to society.

\section{Textbook Avoidance}

It follows from other attributes that thematically schooled undergraduates are ill-served by textbook approaches to learning. Few best-selling college textbooks afford the space to do justice to the thematic or historical dimension, in their compulsion to cover all corners of a discipline in a snapshot of current understanding within a field (Kuhn, 1996). By nature, textbooks are disciplineconstrained rather than interdisciplinary. Perpetually obsolescing textbooks sell for exorbitant prices, yet provide students neither the qualities of original scholarship past nor truly current surveys of processes of inquiry. Instead of textbooks, anthologies, review articles, chronicles, and offprints are materials of choice for theme schools' instructional support.

\section{Extramural Connections and Academic Outreach}

Because of their extensive reliance on resources external to traditional campuses, and because of the siteindependent and transportable nature of their learning strategies, undergraduate theme schools and thematic classes travel well. In Alaska (Cases 2 and 3, above) seminar instruction originates simultaneously from several sites, and reaches students at many other sites around the state through its MSMIC format. Admittedly, neither the Arctic Institute's NPDS Theme School nor the Nickle Arts Museum's Theme School in Museum and Heritage Studies began in Alaska's extramural configuration for distance delivery of seminars. Nevertheless, students themselves work with far-flung institutions and communities during off-campus internship projects to meet requirements for practicum credits. We envision that today's theme school developments may naturally become more outreaching, providing more extramural connections for undergraduate endeavour.

\section{Community Approach}

The aim of the Arctic Institute's NPDS Theme School is to build citizens. It seeks students who will put the common interest ahead of self-interest; women and men who, during and after their undergraduate studies, commit themselves to community development. Unlike other university programmes modeled on a menu-based approach, where students pick courses to suit their major, the theme school takes a communitybased approach, where students from diverse disciplines ideally come together at the beginning of the programme and stay together for its duration, learning from each other and growing in both intellectual and interpersonal skills. As noted above, for example, NPDS Theme School students undergo interviews prior to acceptance. Interviews convey to students the demanding nature of the programme, while gauging each student's commitment to community development.

Students in Alberta's Museum and Heritage Studies Theme School and in Alaska's Museum Studies programme are steadily coached in much the same way: museum career work is emphatically portrayed as a "calling" (Burcaw, 1983:186; Norton and Crowell, 1997) and as a path to rewards in dedicated community enterprise, where individual financial gain is rarely a primary goal.

Even single thematic courses in Alaska encourage this community-based construct. Especially when drawn together from all corners of the state by the MSMIC format, students who are denied traditional campus-cohort identities ("Stanford, Class of '98") substitute a group identity and coherence, by celebrating the diversity of perspectives within the group itself. Can a more desirable outcome be imagined?

If our community-based approach sounds selfrighteous, we point out that coming years will witness dozens of processes that will demand dedicated community leadership, such as the emergence of Nunavut and the 
adjustment of Alaska's North Slope to something besides a petroleum-based economy.

\section{Internship}

The minor degree programme ideally includes theme school courses, thematic seminars, and student research projects, and culminates with internship opportunities. Theme school courses mobilize previously untapped teaching resources by drawing faculty from initiativetaking institutes. The course work is sufficiently flexible to provide for seminar discussions, individual research, self-directed inquiry, and group workshops. The internship programme provides students with both intimate knowledge of connected institutes' activities and relevant employment experience. Four NPDS students completed internships in 1996 (AINA, 1996c), and internship is essential in Museum Studies' contributions to our paradigm (Norton and Crowell, 1997). In northern contexts, where unemployment is high, and in circumstances (such as currently in Canada) where record unemployment afflicts recent graduates, theme schools seek to be employment-directed.

\section{CONCLUSIONS AND INVITATION TO COMMENT}

Our enthusiasm for students' responses to the theme school paradigm is unreserved. Likewise, we are gratified by the patient tolerance with which our respective academic institutions have indulged our undertakings. As to prospects for wider adoption of the theme school paradigm, however, our optimism is guarded. Even if our delight proves to be infectious, we foresee neither sudden nor massive replacement of traditional undergraduate disciplinary programs by the theme school paradigm. Our experiences suggest instead that theme schooling adds momentum to students' travel along their main disciplinary routes. We are also mindful that the early stages of trying any new paradigm for instruction and learning require educators to sustain a far-sighted vision, for the dividends lie well beyond a narrow focus on annual budget cycles.

The Arctic Institute of North America, on the other hand, is like a pontoon bridge that floats high on the twin buoyancies of a "can-do" attitude and interdisciplinary thinking. AINA also exemplifies moorings by the extramural connections that we identify as mainstays for thematic enterprise. Perhaps AINA is ideally positioned to showcase to friends of higher education the long-term proposition that the theme school paradigm is itself like a floating bridge, both in its mobility and in effectively achieving more with less. If the proposition stimulates vigorous comment, we shall count it as yet another dividend accruing to our thematic investments of abiding faith in undergraduate students and in their creative diversity.

\section{REFERENCES}

AINA (Arctic Institute of North America). 1996a. What's new. Information North 22(2):7.

1996b. What's new. Information North 22(3):7.

1996c. What's new. Information North 22(4):7.

BURCAW, G.E. 1983. Introduction to museum work. 2nd ed. Nashville: American Association for State and Local History Press.

EDEY, M.A., and JOHANSON, D.C. 1989. Blueprints: Solving the mystery of evolution. Toronto: Penguin.

ELIOT, T.S. 1932. Selected essays. London: Faber \& Faber Ltd.

KASSAM, K-A.S. 1994. Letter of Intent for Access Funds: Theme School. Prepared for Dr. Cooper Langford, University of Calgary. Unpubl. ms. Available from the Arctic Institute of North America, The University of Calgary, 2500 University Dr. N.W., Calgary, Alberta T2N 1N4, Canada.

- 1995. Theme School on Northern Planning and Development Studies based at the Arctic Institute of North America: Course outlines. Unpubl. ms. Available from the Arctic Institute of North America, The University of Calgary, 2500 University Dr. N.W., Calgary, Alberta T2N 1N4, Canada.

KUHN, T.S. 1996. The structure of scientific revolutions. 3rd ed. Chicago: University of Chicago Press.

MAYR, E. 1991. One long argument: Charles Darwin and the genesis of modern evolutionary thought. Cambridge: Harvard University Press.

McMASTER UNIVERSITY. 1995. 1995-96 undergraduate calendar. Hamilton: McMaster University.

NORTON, D.W., ed. 1992. Arctic Uumaruq 1990-Arctic alive. Barrow: North Slope Borough Higher Education Board.

_ 1997. Development of multi-site, multi-instructor courses (MSMICs) in Alaska. Unpubl. ms. Available from the Arctic Institute of North America, The University of Calgary, 2500 University Dr. N.W., Calgary, Alberta T2N 1N4, Canada.

NORTON, D.W., and CROWELL, A. 1997. Museum Studies: Diversity and convergence in pre-baccalaureate programs. Unpubl. ms. Available from the Arctic Institute of North America, The University of Calgary, 2500 University Dr. N.W., Calgary, Alberta T2N 1N4, Canada.

O'NEILL, D. 1994. The firecracker boys. New York: St. Martin's. O'SULLIVAN, T., HARTLEY, J., SAUNDERS, D., MONTGOMERY, M., and FISKE, J. 1994. Key concepts in communication and cultural studies. 2nd ed. London: Routledge.

SPIESS, P.D. 1996. Museum studies: Are they doing their job? Museum News 75(4):32-40.

David W. Norton teaches Natural Sciences and Museum Studies at Ilisagvik College in Barrow, Alaska.

Karim-Aly S. Kassam is the Director of the Theme School in Northern Planning and Development Studies at the Arctic Institute of North America, The University of Calgary. 